\title{
Dexamethasone Does not Compensate for Local Anesthetic Cytotoxic Effects on Tenocytes: Morphine or Morphine Plus Dexamethasone May Be a Safe Alternative
}

\author{
Anne Lene Oeyen, M.D., Jörn Kircher, M.D., Ph.D., Melanie Vogl, M.D., Irina Ickert, M.D., \\ Nani Osada, Ph.D., Rüdiger Krauspe, M.D., Prof., Bernd Bittersohl, M.D., Ph.D., and \\ Monika Herten, Ph.D.
}

\begin{abstract}
Purpose: The purposes of this in vitro study were to investigate whether the addition of dexamethasone can compensate for any cytotoxic effects of the amide-type local anesthetics (LA) bupivacaine and ropivacaine and whether morphine and morphine-6-glucuronide (M6G) may be a safe alternative for peritendinous application. Methods: Biopsies of human biceps tendons $(n=6)$ were dissected and cultivated. Cells were characterized by the expression for tenocyte markers, collagen I, biglycan, tenascin C, scleraxis, and RUNX via reverse transcriptase-polymerase chain reaction and immunohistochemistry. Tenocytes were incubated with bupivacaine, ropivacaine, morphine, M6G, or a saline control with and without addition of dexamethasone for 15, 60, or $240 \mathrm{~min}$. Cell viability was determined by quantifying the presence of adenosine-triphosphate. Results: Significant time-dependent cytotoxic effects were observed for LA after all exposure times. After 15, 60, and 240 minutes, cell viability decreased to $81.1 \%, 49.4 \%$ and $0 \%(P<.001)$ for bupivacaine and to $81.4 \%, 69.6 \%$, and $9.3 \%(P<.001)$ for ropivacaine compared to saline control. Dexamethasone did not compensate for these cytotoxic effects. Cell viability was not affected after 15, 60-min exposures to morphine and M6G but decreased significantly $(P<.001)$ after 240 minutes compared to saline control. However, in combination with dexamethasone, tenocyte viability was significantly increased at all times for morphine $(P<.01)$ and at 15 and 60 minutes for M6G $(P<.01)$. Conclusions: The results showed that amide-type LA have a time-dependent cytotoxic effect on human tenocytes in vitro, which could not be compensated for by dexamethasone, whereas morphine and M6G had no cytotoxic effects on tenocytes after 15 and 60 minutes. The addition of dexamethasone to morphine and M6G had a positive effect on viability, which increased significantly compared to the opioids. Clinical Relevance: It is known that amide-type local anesthetics used for local joint analgesia have chondrotoxic side-effects. The combined application of morphine and dexamethasone may be a safe alternative.
\end{abstract}

\section{Introduction}

I ntraarticular, periarticular, and peritendinous injections with amide-type local anesthetics (LA) and/ or corticosteroids are performed for analgesia and to inhibit inflammation in patients with substantial joint pain (postoperative, degenerative, and inflammatory diseases). Although analgesia is required for early rehabilitation and prevention of joint stiffness, studies

Department of Orthopedic and Trauma Surgery, Caritas-Klinik Maria Heimsuchung Berlin-Pankow, Berlin, Germany (A.L.O.); Department of Shoulder and Elbow Surgery, ATOS Klinik Fleetinsel Hamburg, Hamburg, Germany (J.K.); Department of Pediatrics, University Hospital Essen, Essen, Germany (M.V.); Department of Medicine II, Rheinlandklinikum Neuss, Neuss, Germany (I.I.); Department of Medical Statistics and Biomathematics (formerly), University of Münster, Münster, Germany (N.O.); Department of Orthopedic Surgery, Medical Faculty, Heinrich-Heine University Düsseldorf, Düsseldorf, Germany (A.L.O., J.K., R.K., B.B., M.H.); Department of Orthopedic and Trauma Surgery, Medical Faculty, Heinrich-Heine University Düsseldorf, Düsseldorf, Germany (B.B); and Department of Trauma, Hand and Reconstructive Surgery, University Hospital Essen, Essen, Germany (M.H.).

The project was funded by the Research Commission of the Medical Faculty of the Heinrich-Heine University Düsseldorf, Germany (J.K.). We acknowledge have proven that amide-type local anesthetics have chondrotoxic side effects, whose intensity depends on the actual active substance, time of exposure, and concentration. ${ }^{1-9}$ Currently, intraarticular injection is only performed under strict indication and is becoming less common, whereas postoperative intra-articular infusion of a local anesthetic via a pain pump has been abandoned because of devastating cases of

support by the Open Access Publication Fund of the University of DuisburgEssen, Germany (M.H.). Full ICMJE author disclosure forms are available for this article online, as supplementary material.

Received May 14, 2021; accepted November 3, 2021.

Address correspondence to Jörn Kircher, M.D., Ph.D., Department of Shoulder and Elbow Surgery, ATOS Klinik Fleetinsel Hamburg, Admiralitätstraße 4, 20459 Hamburg, Germany.E-mail: j-kircher@web.de.

(C) 2021 THE AUTHORS. Published by Elsevier Inc. on behalf of the Arthroscopy Association of North America. This is an open access article under the CC BY-NC-ND license (http://creativecommons.org/licenses/by-nc-nd/4.0/). 2666-061X/21681

https://doi.org/10.1016/j.asmr.2021.11.004 
glenohumeral chondrolysis. ${ }^{10-17}$ Recent research has confirmed a similar cytotoxic effect of LA on tenocytes in vitro. ${ }^{6,18-21,22}$ In vivo studies evaluating the cytotoxic profile of LA in tendons are limited and present partially conflicting results after periarticularly injected LA. Whereas Friel et al. found no effects on rotator cuff tendons in rabbits after continuous subacromial bupivacaine infusion $(.25 \%$ with epinephrine for $48 \mathrm{~h}$ ) after 2 weeks, Lehner et al. demonstrated that a single injection of $.5 \%$ bupivacaine caused short-term changes in rat Achilles tendons. ${ }^{23,24}$ Similarly, Nuelle et al. noted significant tenotoxicity of the supraspinatus tendon after a single injection of a combination of bupivacaine in low concentration $(.06 \%)$ and corticosteroids into the subacromial space in adult dogs at day $7 .^{25}$

Corticosteroids still play a major role in the management of all kinds of inflammatory disease, especially in the musculoskeletal system. ${ }^{26-29}$ In multiple clinical trials, the addition of corticosteroids extended the duration of the analgesic effect of LA in regional blocks (brachial plexus). ${ }^{30-34}$ Corticosteroid adjuvants in periarticular analgesic injections are of interest; in fact, several clinical studies have reported a slight reduction in postoperative pain or prolongation of analgesic effect with the addition of corticosteroids to periarticular and intra-articular LA. ${ }^{35-42}$

Alternatives to LA with fewer side-effects are urgently needed. The mode of action of opioid drugs differs from that of amide-type local anesthetics and may be a safe and potent alternative for particular application. Morphine has been proven to provide sufficient analgesic effect in periarticular application ${ }^{43,44}$ and intraarticular application. ${ }^{45-50}$ Experimental trials have shown that morphine is significantly less chondrotoxic ${ }^{1,51,52}$ and tendotoxic ${ }^{20}$ compared to LA.

Morphine-6-glucuronide, an active metabolite of morphine, is an effective analgesic with a slower onset but and a longer analgesic effect/duration of action compared to morphine when administered intravenously or subcutaneously. Side effects, most importantly postoperative nausea and vomiting, occur less frequent after M6G treatment. ${ }^{53}$ Studies suggest that the metabolite M6G instead of morphine itself is the major contributor of analgesic effect via $\mu$-opioid receptors after administration of morphine to patients, irrespective of the route of administration. ${ }^{53,54}$

In the present study, we investigated whether the addition of dexamethasone can compensate for any cytotoxic effects of the amide-type LA (bupivacaine and ropivacaine) and whether opioids (morphine and morphine-6-glucuronide) may be a safe alternative for peritendinous application. ${ }^{1}$

Our hypothesis is, that morphine and M6G do not reduce the viability of the primary human tenocytes, in contrast to the LA bupivacaine and ropivacaine and that the addition dexamethasone can compensate for the cytotoxicity caused by the LA.

\section{Materials and Methods}

\section{Study Population}

The study was approved by the local Ethics Committee of the Heinrich-Heine-University Düsseldorf (\#3506). Informed consent was gathered prior to the study initiation from the patient, caregiver, or legal representative. The tendon samples were obtained from patients without preexisting illnesses (i.e., metabolic syndrome, diabetes, coronary heart diseases, acute or chronic infections, and cancer), who were scheduled to undergo arthroscopic surgery for rotator cuff repair or open shoulder surgery, such as hemiarthroplasty following humeral head fractures. Exclusion criteria were the presence of substantial degenerative tendon changes, infections, or previous surgery at the site of biopsy. Proximal explants of human long biceps tendons were obtained from 6 patients in total ( 2 male and 4 female), with an average age of $48.5 \pm 18.9$ years (range: $24-75$ years). A case number estimation for unrelated samples and continuous targets was performed using the program "jumbo" from the University of Münster, Münster, Germany. ${ }^{55}$ For the power analysis, we used our previous study as a guide, in which the effect of LA and morphine on the viability of chondrocytes was tested. ${ }^{1}$ The case number estimation resulted in a maximal case number of 5 ; we decided to take $n=6$.

\section{Tenocyte Harvesting and Culture}

Visually intact proximal explants of the long biceps tendons were washed 3 times in sterile PBS (Gibco, Deisenhofen, Germany). Tenocytes were harvested by cell migration, as previously described. ${ }^{56,57}$ The tendons were dissected into $30-60 \mathrm{~mm}^{3}$ fragments and cultivated in culture flasks using Dulbecco's Modified Eagle Medium (DMEM; Gibco) with $4.5 \mathrm{~g} / \mathrm{L}$ glucose, $20 \%$ fetal bovine serum (Gibco), 100 units/mL penicillin, $100 \mu \mathrm{g} / \mathrm{mL}$ streptomycin and $2 \mathrm{mM}$ glutamine (Gibco) culture conditions analogous to chondrocytes, as previously described. ${ }^{1}$ The culture conditions were $8.5 \%$ $\mathrm{CO}_{2}$ at $37^{\circ} \mathrm{C}$. No further growth or differentiation factors were added. The medium was changed twice per week. Tenocytes continuously migrated from the tendon fragments and adhered to the culture flask. Immediately before the cells displayed a confluent monolayer (defined as passage zero, or P0), they were trypsinized $(.05 \%$ trypsin $/ .02 \%$ ethylenediaminetetraacetic acid (EDTA) (Gibco) counted and either cryopreserved or subcultured directly into passage one (P1). Cryopreservation of cells (P0) was performed in $90 \%$ FCS $+10 \%$ DMSO (Gibco) at $-80^{\circ} \mathrm{C}$ in 5 of 6 patients. For the experiments, the cells were thawed 
and subcultured as P1. The cells of all 6 patients were subsequently subcultured into passage two (P2), which was used for the experiments.

\section{Cell Characterization}

The tenocytes of P2 of all 6 patients were characterized by their expression via RT-PCR and protein profiles via immunocytochemisty for five typical tenocyte markers, collagen I, biglycan, tenascin C, scleraxis, and RUNX. GAPDH was used as a housekeeping gene.

\section{Reverse Transcriptase Polymerase Chain Reaction}

In order to control the tenocyte genotype, RNA was extracted from 6 wells $\left(\sim 7.4 \times 10^{4}\right.$ tenocytes in total $)$ using the RNeasy mini kit (Qiagen, Hilden, Germany), according to the manufacturer's instructions. RNA concentration was measured by a photometer (NanoDrop, Peqlab, Erlangen, Germany). For PCR, the OneStep RT-PCR Kit (Qiagen) was used in a thermocycler (Allignet Technologies, Ratingen, Germany), according to the manufacturer's instructions. The PCR program consisted of the reverse transcription at $50^{\circ} \mathrm{C}$ for 30 minutes, the initial PCR activation at $95^{\circ} \mathrm{C}$ for $15 \mathrm{mi}-$ nutes, 35 times $(35 \times)$ the following three-step-cycle: 1) denaturation at $94^{\circ} \mathrm{C}$ for 30 seconds, 2) annealing at $55^{\circ} \mathrm{C}$ for 30 seconds, and 3) extension at $72^{\circ} \mathrm{C}$ for 60 seconds with a final extension at $72^{\circ} \mathrm{C}$ for 10 minutes. PCR products were separated via agarose gel electrophoresis. The primers for Aggrecan, Biglycan, Decorin, Collagen I and Tenascin $\mathrm{C}$ were used as described before. ${ }^{58}$ GAPDH $\left(5^{\prime}\right.$-ctc aag atc agc aat gcc, $3^{\prime}$-gat ggt aca tga caa ggt gc) was used as housekeeping gene.

\section{Immunocytochemical Staining}

In order to control the tenocyte phenotype, the cells were immunocytochemically stained for tenocyte markers. The cells of the second passage were seeded onto 24 -well plates in a cell density of $3 \times 10^{3}$ cells $/ \mathrm{cm}^{2}$ and cultured for 4 days. After fixation with $4 \%$ buffered paraformaldehyde (Rotifix, Carl Roth, Germany), endogenous peroxidase was blocked with .3\% hydrogen peroxide for 30 minutes. After washing, the fixed cells were incubated with the primary monoclonal or polyclonal antibodies at $5^{\circ} \mathrm{C}$. The monoclonal antibodies were collagen I, (1:100 dilution, AbDSerotec, Puchheim,
Germany), biglycan (1:200 dilution, Abcam, Cambridge United Kingdom), and tenascin C (1:100 dilution, Acris Antibodies, Hiddenhausen, Germany). The polyclonal antibodies were Runx 2 ( 1:500 dilution, rat-anti-human; R\&D Systems, Minneapolis, MN) and scleraxis (1:100 dilution, rabbit-anti-human; Acris Antibodies). The respective negative controls were incubated in comparable concentrations of either mouse IgG1, IgG2a (Vector Laboratories, Burlington, CA), polyclonal rat or rabbit serum in antibody diluent (Dako, Agilent, Santa Clara, CA) at $5^{\circ} \mathrm{C}$. After washing, a secondary anti-mouse or anti-rat biotin-labeled antibody (Vector Laboratories) was added for 60 minutes at RT. The antibody-antigen complex was visualized using streptavidin peroxidase (Vector Laboratories) and diaminobenzidine (SigmaAldrich, Steinheim, Germany) as chromogen.

\section{Experimental Setup}

Tenocytes of $n=$ six donors (P2) were seeded onto 24well plates (Nunc, Darmstadt, Germany) in a concentration of $3 \times 10^{3}$ cells $/ \mathrm{cm}^{2}$ using the DMEM, as described before. At day 4, the cells were incubated with the substances, and finally, they were fixed for immunocytochemistry or conserved for PCR. The cell supernatant was removed for incubation, and the cells were exposed to the following substances for increasing incubation times (15, 60 , and 240 minutes) (Table 1). The cells were incubated with the anesthetics bupivacaine $(5 \mathrm{mg} / \mathrm{mL}$; BucainActavis, Actavis, Langenfeld, Germany), ropivacaine (7.5 mg/mL; Naropin, AstraZeneca, Wedel, Germany), morphine $(10 \mathrm{mg} / \mathrm{mL}$, diluted with saline; Merck Serono Darmstadt, Germany), morphine-6-glucuronide (M6G; 5 $\mathrm{mg} / \mathrm{mL}$; diluted with saline; Sigma-Aldrich, Deisenhofen, Germany) or saline as a control. Furthermore, dexamethasone $(2.5 \mathrm{mg} / \mathrm{mL}$; Lipotalon, Merckle Recordati, Ulm, Germany) was also added to the cells. Combinations of dexamethasone and local anesthetic were diluted $1: 10$ (dexamethasone: local anesthetic) to mimic clinical practice. ${ }^{6}$ Dexamethasone alone was diluted with saline. These concentrations of the LA have been used in previous and comparable in vitro studies with chondrocytes $^{1,7,52,59}$ and tenocytes ${ }^{18-20,60}$, as well as intraarticular and periarticular ${ }^{38,45,61,62}$ in clinical studies. Furthermore, these are concentrations that can be used for anesthesiologic field blocks with LA in surgery. ${ }^{63,64}$

Table 1. Incubation Scheme and the Concentrations Used

\begin{tabular}{llllcc}
\hline & \multicolumn{3}{c}{ Without dexamethasone } & \multicolumn{2}{c}{ with dexamethasone $0.23 \mathrm{mg} / \mathrm{ml}=0.023 \%$} \\
\hline Incubation time final concentration & l5 min & $60 \mathrm{~min}$ & $240 \mathrm{~min}$ & $\mathrm{l}$ min & $60 \mathrm{~min}$ \\
Bupivacaine $5 \mathrm{mg} / \mathrm{ml}=0.5 \%$ & $\mathrm{X}$ & $\mathrm{X}$ & $\mathrm{X}$ & $\mathrm{X}$ & $\mathrm{X}$ \\
Ropivacaine $7.5 \mathrm{mg} / \mathrm{ml}=0.75 \%$ & $\mathrm{X}$ & $\mathrm{X}$ & $\mathrm{X}$ & $\mathrm{X}$ & $\mathrm{X}$ \\
Morphine $0.5 \mathrm{mg} / \mathrm{ml}=0.05 \%$ & $\mathrm{X}$ & $\mathrm{X}$ & $\mathrm{X}$ & $\mathrm{X}$ & $\mathrm{X}$ \\
Morphine-6 glucuronide $0.5 \mathrm{mg} / \mathrm{ml}=0.05 \%$ & $\mathrm{X}$ & $\mathrm{X}$ & $\mathrm{X}$ & $\mathrm{X}$ & $\mathrm{X}$ \\
control saline $\mathrm{NaCl} 9 \mathrm{mg} / \mathrm{ml}=0.09 \%$ & $\mathrm{X}$ & $\mathrm{X}$ & $\mathrm{X}$ & $\mathrm{X}$ & $\mathrm{X}$ \\
\hline
\end{tabular}


For each concentration, time point, and patient, $n=6$ wells were used. After incubation with the anesthetics, the cells were washed with PBS and cultured further in a fresh medium without additives. Three days after incubation, cell viability was measured in $n=6$ wells per substance and time point for each of $n=6$ donors (= 36 wells in total per condition) (Table 1$)$.

To exclude any side effects, the final anesthetic and dexamethasone solutions in culture medium were controlled for osmolarity (Osmometer, Knauer, Oberursel, Germany) and $\mathrm{pH}$ value. Cell culture medium is designed to have osmolarity in the range of 260 and 320 milliosmoles (mOsm), basically to mimic the osmolarity of serum at $290 \mathrm{mOsm} / \mathrm{kg} .{ }^{65}$ For ropivacaine and bupivacaine, the values were 301.7 and 290.0 mosmol/L. After the addition of dexamethasone, the values were 303.7 and $288.7 \mathrm{mosmol} / \mathrm{L}$. Morphine and M6G yielded values of 313.7 and $292.7 \mathrm{mosmol} / \mathrm{L}$. The addition of dexamethasone did not change osmolarity, and the $\mathrm{pH}$ values were in the range of 6.0-6.5.

\section{Cell Viability Measurement}

Cell viability was assessed using the CellTiter-Glo luminescent cell viability assay (Promega, Mannheim, Germany), as described before. ${ }^{1,66}$ This assay quantifies the presence of adenosine triphosphate (ATP), which identifies the metabolically active cells. Luminescence produced by the luciferase-catalyzed reaction of luciferin and ATP was measured using a multilabel plate reader (VICTOR3; PerkinElmer LAS, Rodgau-Jügesheim, Germany).

One major advantage of this method is that it is fast, the background interference (autofluorescence from compounds, media, and cells) is low, and it generally provides a much broader dynamic range and higher sensitivity. In brief, the medium was removed, $50 \mu \mathrm{L}$ PBS and $150 \mu \mathrm{L}$ CellTiter-Glo reagent was added into each well. After an incubation period of 20 minutes at room temperature, the luminescent signal was recorded in counts per second. ATP standard curves were plotted with defined ATP concentrations (25-4000 $\mathrm{nM})$ for each measurement, and the number of cells was calculated with standard measurements performed for each patient with defined numbers of tenocytes from the monolayer culture (standard curves with $7.8 \times 10^{2}, 1.5 \times 10^{3}, 3.12 \times 10^{3}$, $6.2 \times 10^{3} 1.25 \times 10^{4}, 2.5 \times 10^{4}, 5 \times 10^{4}$, and $1.0 \times 10^{5}$ cells). The mean intra-assay coefficient of variability of the CellTiter-Glo luminescent cell viability assay was $1.28 \%$ in the preliminary experiments $(n=3 ; .88-1.62$ $\%)$. The mean inter-assay coefficient of variability of the CellTiter-Glo luminescent cell viability assay of the main experiments was $2.49 \%(n=5, .93-3.35 \%)$.

\section{Statistics}

The statistical analyses were performed using SPSS software (SPSS 27.0, Chicago, IL; Microsoft Excel,
Redmond, WA). Data were expressed as means \pm SD for cell viability. For the statistical comparisons between the different independent groups, the nonparametric Mann-Whitney $U$-test was used to compare cell viability after incubation with the different substances. To determine the influence of dexamethasone on the incubation with LA (bupivacaine/ropivacaine) or morphine/M6G, the $t$-test for equality of means for independent samples was used. The level of significance was set at $P<.05$.

\section{Results}

\section{Cell Proliferation and Characterization}

The average generation time of the first two passages of cells was $3.46 \pm 1.00$ days; the range was 2.84-5.45 days for $n=6$ donors. The cells were characterized as tenocytes by the expression of the tenocyte markers biglycan, runx, scleraxis, collagen $\mathrm{I}$, and tenascin $\mathrm{C}$ on the protein level, as shown via immunohistochemical staining of the typical tenocyte marker (Fig 1). Also, on the mRNA level, the expression of the tenocyte markers could be detected in 5 of the 6 patients. For one patient, the amount of mRNA was not sufficient for all PCRs (Fig 2).

\section{Cell Viability After Exposure}

There was a significant time-dependent decrease in the tenocytes' cell viability after exposure to amide-type local anesthetics (bupivacaine and ropivacaine) (Fig 3). After 15, 60, and 240 minutes of incubation with bupivacaine, cell viability decreased to $81.1 \pm 18.9 \%$ $(P<.001), 49.4 \pm .22 \%(P<.001)$ and $.0 \%$ in relation to the saline control $(=100 \%)$. Ropivacaine caused a similar decrease in tenocyte viability after short-term incubation but did not lead to complete cell death after long-term incubation. After incubation for 15, 60, and 240 minutes, cell viability decreased to $81.4 \pm 18.2$ $\%(P<.001), 69.6 \pm 14.0 \%(P<.001)$ and $9.2 \pm 3.1 \%$ $(P<.001)$ in relation to the saline control.

There was no statistical difference in cell viability after incubation with morphine and M6G for 15 and 60 minutes compared to the saline control (morphine: $96.1 \pm 16.1 \%$ and $100.5 \pm 15.3 \%$, M6G: $97.0 \pm 19.0 \%$ and $99.2 \pm 18.4 \%)$. After 240 minutes, the viability decreased to $78.6 \pm 6.0 \%$ (morphine, $P<.001$ ) and to $86.1 \pm 8.5 \%$ (M6G, $P<.01)$ compared to saline control. The further time-dependent decrease at $240 \mathrm{mi}-$ nutes, compared to viability after 15 and 60 minutes, was only significant for morphine (Fig 3).

Exposure to dexamethasone alone (without other additives) had no significant effect on viability after any exposure time $(t=15: 101.6 \pm 20.5 \% ; t=60: 104.2$ $\pm 17.3 \% ; t=240: 99.3 \pm 19.7 \%$ compared with saline as control. 
Fig. 1. Immunohistochemical staining of tenocyte markers: biglycan (A), Runx (B), scleraxis (C), collagen I (D), unstained control $(\mathrm{E})$, tenascin $\mathrm{C}(\mathrm{F})$.

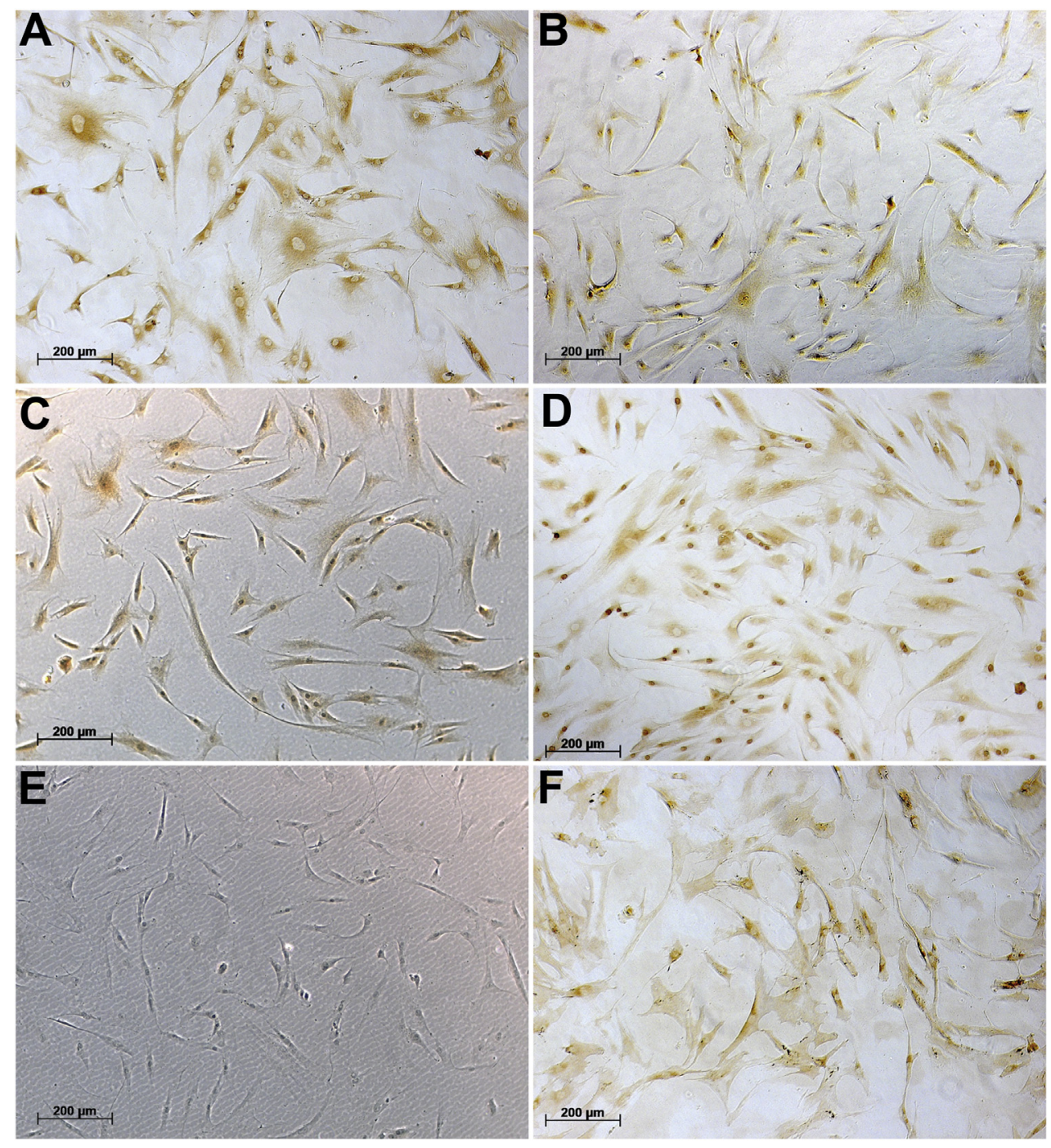

The cytotoxic effects of bupivacaine and ropivacaine were not compensated for by the addition of dexamethasone. In contrast, after incubation for 15 minutes, the viability of the tenocytes decreased significantly, with the addition of dexamethasone compared to when they were incubated with the anesthetics alone (bupivacaine: $81.1 \pm 19.0 \%$ vs $50.1 \pm 22.5 \%[P<.001]$, ropivacaine $81.4 \pm 18.2 \%$ vs $69.5 \pm 19.2 \%[P<.05])$ (Fig. 4A). After a more prolonged incubation (60 and 240 minutes), there was no significant difference in the viability with or without the addition of dexamethasone. (Fig 4, B and C).

The addition of dexamethasone to morphine and M6G had a positive effect on the viability of tenocytes, which increased significantly for all incubation times compared to the opioids alone. It was even higher than the saline control $(=100 \%)$ for most time points (Fig 4, $\mathrm{A}-\mathrm{C}$ ). The values for morphine and dexamethasone were $110.7 \pm 18.5 \% \quad(P<.01), 116.5 \pm 23.2 \%$ $(P<.001)$, and $112.4 \pm 19.2 \%(P<.001)$ after 15,60 , and 240 minutes and with $>100 \%$ higher than the saline control. Also combined incubation of M6G and dexamethasone displayed increased cell viability with $111.1 \pm 21.3 \%(P<.01), 110.6 \pm 16.4 \%(P<.001)$, and $100.0 \pm 20.1 \%$ after 15,60 , and 240 minutes compared to the saline control $(=100 \%)$.

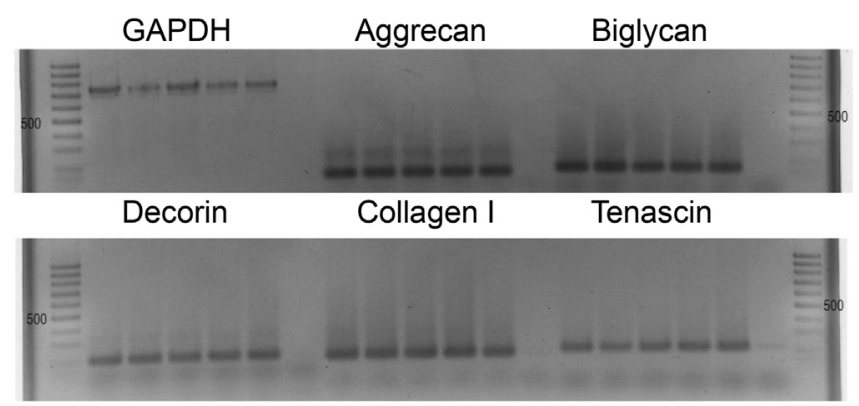

Fig 2. Expression profile of typical tenocyte markers. In the cells of all five patients tested, the tenocyte markers were expressed in comparable intensities. 


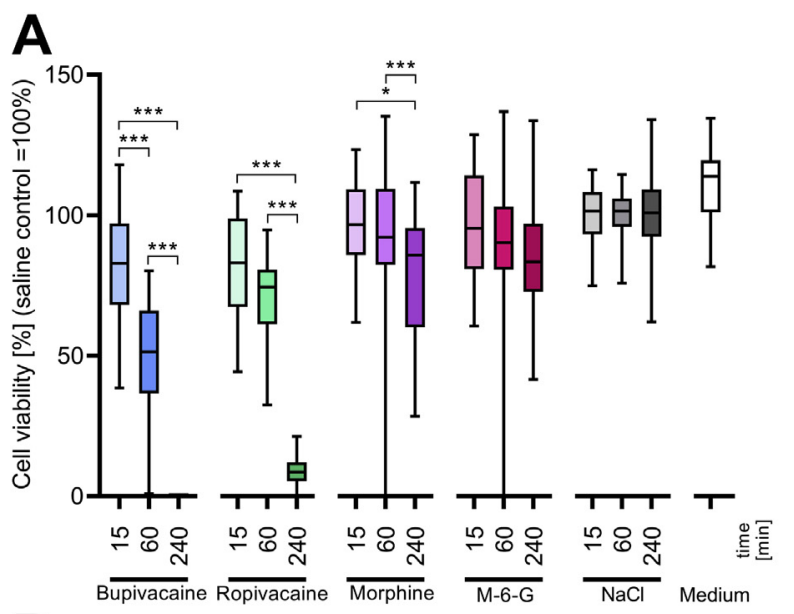

B

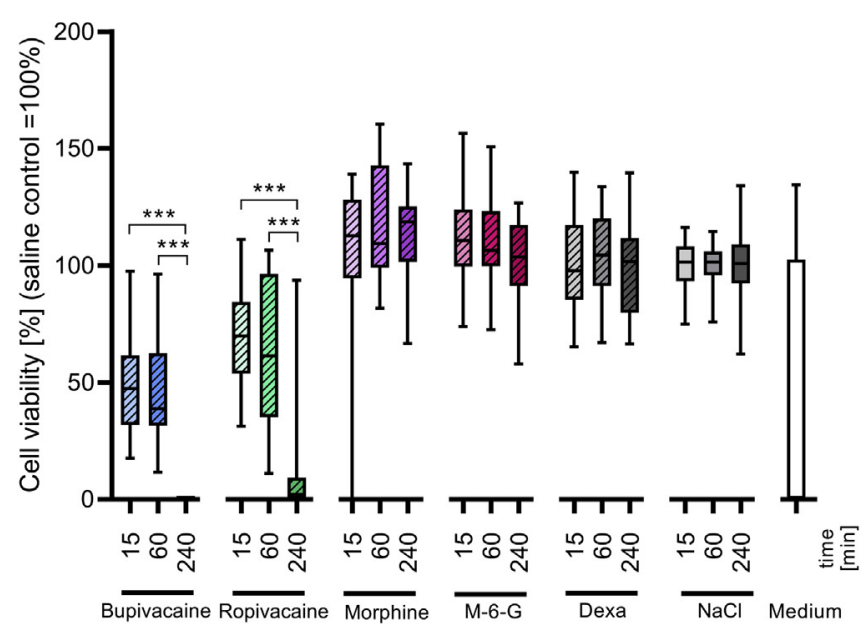

Fig 3. Cell viability after exposure to all substances. (A) Influence of different incubation times $(15,60$, and $240 \mathrm{mi}-$ nutes) with anesthetics on the viability of tenocytes in relation to the saline control $(=100 \%)$. (B) Influence of different incubation times $(15,60$, and 240 minutes) with anesthetics combined with dexamethasone on the viability of tenocytes in relation to the saline control. The box plots span the interquartile range. The vertical line inside the box represents the mean. The whiskers extend to the highest and lowest observations. Experiments reveal the means \pm SD of $n=6$ wells per patient ( $n=6$ patients) for each time point and substance, amounting to a total of 36 wells per time point and substance, except for morphine and M6G with $n=5$ patients at $60 \mathrm{mi}$ nutes with a total of 30 wells. Statistical significances are expressed as ${ }^{*} P<.05 ;{ }^{*} P<.01 ; * * * P<.001$.

\section{Discussion}

The tested opioid drugs, morphine and M6G, showed no cytotoxic effects on human tenocytes after shorttime exposure of up to 60 minutes, as cell viability was as high as in the saline control. After long-time exposure to opioids for 240 minutes, the slightly decreased cell viability was counterbalanced by the addition of dexamethasone. We observed severe cytotoxic effects of LA after incubation for $240 \mathrm{~min}$, resulting in complete cell death in bupivacaine, and nearly complete cell death in ropivacaine, which could not be compensated for by the addition of dexamethasone. Dexamethasone alone had no significant impact on the viability of the tenocytes compared to saline control in our experiments.

In our study, we observed the absence of relevant cytotoxic effects of opioids after short-term exposure. These findings are in line with the results of the study by Haasters et al., who did not find any adverse effect for morphine $(.25 \mathrm{mg} / \mathrm{mL}, 120$ minutes $)$ on the viability of human tendon stem/progenitor cells from hamstring tendons. ${ }^{20}$ However, in contrast to Haasters, we observed a low, but significant, decrease in viability after longer exposure (240 minutes) to both opioids. This might be due to the different time points for viability measurement (Haasters after 0-6 hours, our study after 72 hours), delayed cytotoxic effects, and the double concentration of morphine $(.5 \mathrm{mg} / \mathrm{mL})$ used in our study. So far, there have been no studies showing the effect of M6G on tenocytes. In previous experiments on human chondrocytes, morphine, as well as M6G (both $.5 \mathrm{mg} / \mathrm{mL}$ ) did not affect viability after 240 minutes of incubation. ${ }^{1}$ Other in vitro studies confirmed this neutral effect of morphine on chondrocyte viability in cocultures of canine cartilage and synovial tissue explants ${ }^{52}$ and on human chondrocytes. ${ }^{67}$

We detected a time-dependent cytotoxicity of LA on tenocyte viability in vitro. Our results confirm previous findings, which demonstrated that 6 hours of exposure to bupivacaine $(5.0 \mathrm{mg} / \mathrm{mL})$ and ropivacaine $(7.5 \mathrm{mg} /$ $\mathrm{mL})$ resulted in total cell death of human hamstring tenocytes. The cytotoxic effects were concentrationand time-dependent. ${ }^{20}$ Other studies have also reported cytotoxic effects of bupivacaine $(5.0 \mathrm{mg} / \mathrm{mL})$ on human rotator cuff tenofibroblasts after 24 hours of exposure, as well as of ropivacaine $(7.5 \mathrm{mg} / \mathrm{mL}) .{ }^{18,21}$ Lower concentrations of bupivacaine up to $.05 \mathrm{mg} / \mathrm{mL}$ and 24 hours incubation time had no toxic effect, whereas concentrations of more than $2.5 \mathrm{mg} / \mathrm{mL}$ were cytotoxic. ${ }^{6,21}$ It can be concluded that the cytotoxic effect of LA on tenocytes depends on the substance (bupivacaine $>$ ropivacaine), concentration and time of exposure. The same has been demonstrated for chondrocytes in various studies. ${ }^{1,3,6,7}$

In our in vitro study, the time-dependent negative effect on cell viability of both bupivacaine and ropivacaine was particularly distinct after the long incubation time of 240 minutes. For bupivacaine, this reduction of tendon cell viability could not observed in vivo, as shown in the study of Lehner et al., who compared cell viability after bupivacaine treatment in vitro and in vivo. In vitro, the rat tendon-derived cells were treated with bupivacaine $(.5 \%$ for $10 \mathrm{mi}-$ nutes), while in vivo, the rats received a single peritendinous injections into the Achilles tendon. ${ }^{24}$ 


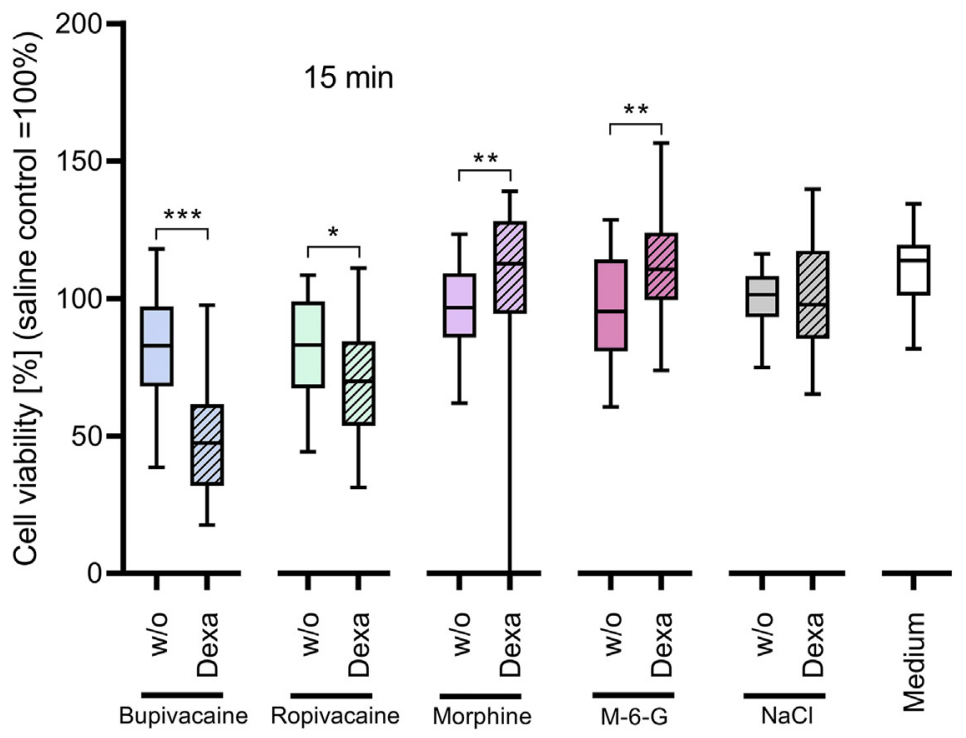

Fig 4. Influence of the addition of dexamethasone. Addition of dexamethasone to tenocytes after incubation with anesthetics for 15 minutes (A), 60 minutes (B), and 240 minutes (C). The box plots span the interquartile range. The vertical line inside the box represents the mean. The whiskers extend to the highest and lowest observations. Experiments reveal the means $\pm \mathrm{SD}$ of $n=6$ wells per patient ( $n=6$ patients) for each time point and substance amounting to a total of 36 wells per time point and substance, except for M6G and M with only $n=5$ patients after $60 \mathrm{mi}$ nutes of exposure. Statistical significances are expressed as ${ }^{*} P<.05 ;{ }^{*} P<.01 ; * * * P<.001$.

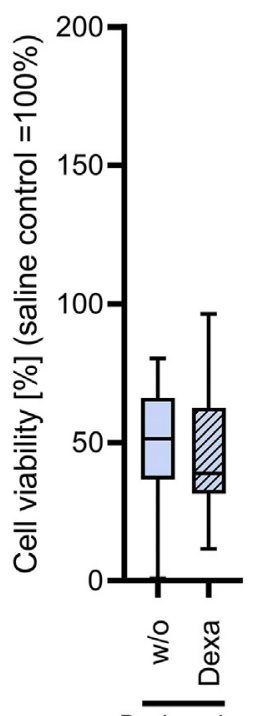

Bupivacaine Ropivacaine
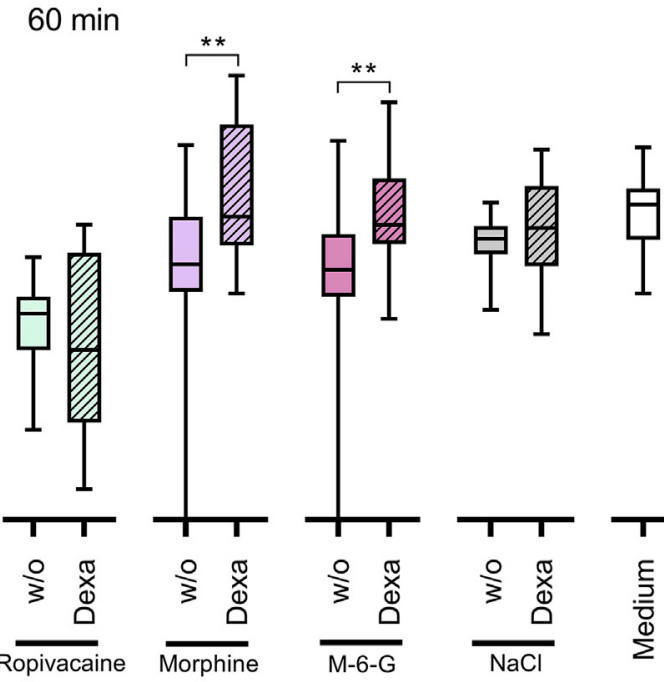

웅

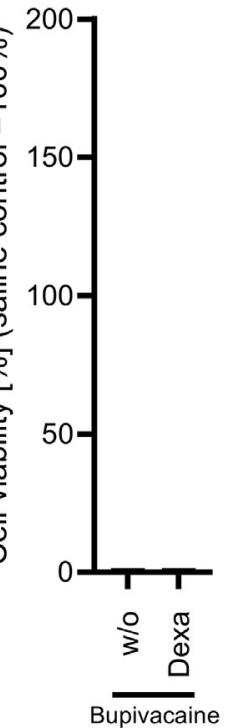

$240 \mathrm{~min}$
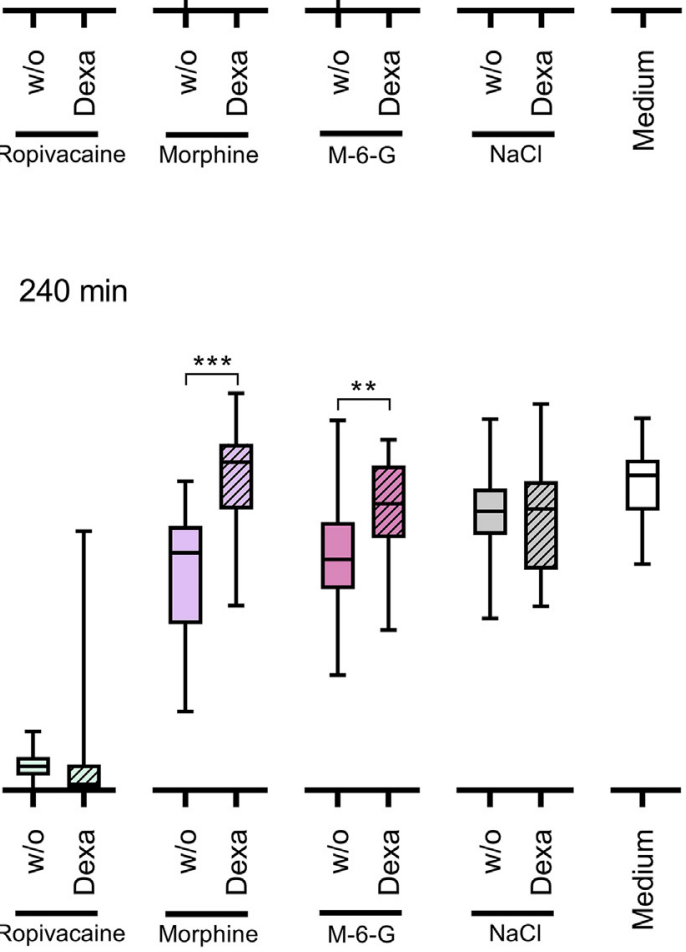
Treatment of rat tendon-derived cells had detrimental effects on cell viability, which could be reduced by $\mathrm{N}$-acetyl-L-cysteine or reduction of extracellular calcium. In vivo, single peritendinous injections had impairing effects on cells within areas of loose connective tissue and elicited considerable, although only temporary, functional damage. It could be shown that bupivacaine induces mitochondrial dysfunction, as well as overproduction of reactive oxygen species (ROS), which cause necrosis or apoptosis., ${ }^{32}$ Other studies also showed that the cytotoxic ROS-mediated effect is potentiated by a higher level of extracellular calcium. ${ }^{68-70}$ The reason for the different observations in vivo and in vitro is most likely the missing extracellular matrix, which may provide protection for tenocytes, thus mitigating the damaging effects observed using in vitro monolayer cell culture models, as postulated by Sherb et al. ${ }^{22}$

In the present study, dexamethasone alone in a concentration of $.23 \mathrm{mg} / \mathrm{mL}$ did not significantly affect the viability of tenocytes regardless of the duration of the exposure time. This observation is in line with previous studies with a similar experimental setup, which reported results for $.25 \mathrm{mg} / \mathrm{mL}$ dexamethasone and 24 hours of incubation ${ }^{6}$ and for $.8 \mathrm{mg} / \mathrm{mL}$ and 30 minutes of incubation. ${ }^{66}$

Our results demonstrated that the tendotoxic effect of bupivacaine and ropivacaine could not be compensated for by the addition of dexamethasone. On the contrary, after incubation for 15 minutes, the tenocytes' viability decreased significantly with the addition of dexamethasone compared to incubation with the LA alone. However, after incubation for 60 minutes with LA and dexamethasone, no differences between the combination and the LA alone were detected. This corresponds to previous findings, in which the combined incubation with dexamethasone and ropivacaine $(.8 \mathrm{mg} / \mathrm{mL}$ and $5.0 \mathrm{mg} / \mathrm{mL}$ ) for 30 minutes also reduced the viability of bovine tenocytes significantly compared to ropivacaine alone. $^{66}$

In all probability, it is the different modes of action by which LA and opioids lead to analgesia that are responsible for the distinct difference in the cytotoxic effects on tenocytes. The opioids morphine and M6G act directly via the $\mu$-opioid receptor as signaling agonists. ${ }^{71,72}$ Morphine has several different roles in cell protection and the modulation of cell death. In a review by Tegeder et al., ${ }^{73}$ several studies reported on the protective and proliferating effect of morphine on different cell types (i.e., immune cells, neurons and glia, endothelial cells and fibroblasts, tumor cells) at low concentrations, while relatively high concentrations in vitro, as well as chronic clinical opioid treatment can lead to inhibition of cell growth. So far, no studies have been published on whether these findings also apply to human tenocytes.
Regarding the mode of action, amide-type local anesthetics influence sodium channels in the cell membrane, leading to an induction of mitochondrial dysfunction, as well as overproduction of ROS, DNA damage, and apoptosis. 3,68,69

Regarding the clinical application of morphine, morphine was only added to a multimodal drug injection and admitted periarticularly. In the most recent study, a mixture of steroids, local anesthetics, NSAIDs, and epinephrine with or without morphine $(.1 \mathrm{mg} / \mathrm{kg})$ was injected periarticularly into randomly assigned patients $(n=100)$ after total hip arthroplasty. The results suggested that the addition of morphine to the multimodal cocktail injection after total hip arthroplasty was not effective for relieving postoperative pain, alleviating swelling, or improving range of motion. ${ }^{74}$

Also, after total knee arthroplasty, the effect of morphine added to periarticular multimodal drug injection (PMDI) or spinal anesthesia on pain management and functional recovery was investigated in $n=$ 100 patients in total. The data revealed that the efficacy of morphine added to periarticular multimodal drug injection was limited and that of morphine added to spinal anesthesia disappeared within $20 \mathrm{~h}$ postoperatively. Adding morphine to PMDI or spinal anesthesia did not improve functional recovery and caused some adverse effects. ${ }^{75}$

\section{Limitations}

There are some limitations to this study. The tenocytes derived from a limited number of healthy individuals. Therefore, interindividual variation in tendon quality and susceptibility to cytotoxic agents cannot be excluded. The age range of the patients and was high (24-75 years). In clinical practice, mean patient age could be higher, resulting in even greater local anesthetic cytotoxicity.

The exposure time and the number of applications in a clinical setting can vary substantially between different individuals, physicians, and locations, due to many heterogeneous factors. We cannot exclude regeneration of the cells after a single exposure, nor can we exclude long-term detrimental effects of a single application to the cells due to the experimental setup.

Another limitation in this study is that only one concentration per local anesthetic was used in the experiments, although lower concentrations have also been used in clinical practice and studies that have lower cytotoxicity profiles (i.e., .25\% bupivacaine and $.2 \%$ ropivacaine). ${ }^{19,21,66}$ We focused on the concentrations that have been used in both clinical practice $^{6,45,61,62}$ and previous studies ${ }^{18-20,60}$ and that are used for anesthesiological field blocks with LA. We used these known cytotoxic concentrations to be able to investigate possible compensatory effects of the addition of corticosteroids. 


\section{Conclusions}

The results showed that amide-type local anesthetics have a time-dependent cytotoxic effect on human tenocytes in vitro, which could not be compensated for by dexamethasone. Morphine and M6G, on the other hand, were found to have no cytotoxic effects on tenocytes after 15 and 60 minutes of exposure. The addition of dexamethasone to morphine and M6G had a positive effect on the viability of tenocytes, which increased significantly compared to the opioids alone.

\section{Acknowledgment}

The authors thank Ms. Sabine Lensing-Höhn of the Orthopedic Department, University Hospital, HeinrichHeine-University Düsseldorf for her technical assistance. We thank Ms. Kaye Schreyer for editorial assistance with the manuscript.

\section{References}

1. Ickert I, Herten M, Vogl M, et al. Opioids as an alternative to amide-type local anaesthetics for intra-articular application. Knee Surg Sports Traumatol Arthrosc 2015;23:2674-2681.

2. Farkas B, Kvell K, Czompoly T, Illes T, Bardos T. Increased chondrocyte death after steroid and local anesthetic combination. Clin Orthop Relat Res 2010;468:3112-3120.

3. Grishko V, Xu M, Wilson G. Pearsall 4th AW. Apoptosis and mitochondrial dysfunction in human chondrocytes following exposure to lidocaine, bupivacaine, and ropivacaine. J Bone Joint Surg Am 2010;92:609-618.

4. Dragoo JL, Korotkova T, Kanwar R, Wood B. The effect of local anesthetics administered via pain pump on chondrocyte viability. Am J Sports Med 2008;36:1484-1488.

5. Kreuz PC, Steinwachs M, Angele P. Single-dose local anesthetics exhibit a type-, dose-, and time-dependent chondrotoxic effect on chondrocytes and cartilage: A systematic review of the current literature. Knee Surg Sports Traumatol Arthrosc 2018;26:819-830.

6. Busse P, Vater C, Stiehler M, et al. Cytotoxicity of drugs injected into joints in orthopaedics. Bone Joint Res 2019;8: 41-48.

7. Breu A, Rosenmeier K, Kujat R, Angele P, Zink W. The cytotoxicity of bupivacaine, ropivacaine, and mepivacaine on human chondrocytes and cartilage. Anesth Analg 2013; 117:514-522.

8. Braun HJ, Wilcox-Fogel N, Kim HJ, Pouliot MA, Harris AH, Dragoo JL. The effect of local anesthetic and corticosteroid combinations on chondrocyte viability. Knee Surg Sports Traumatol Arthrosc 2012;20:1689-1695.

9. Chu CR, Izzo NJ, Coyle CH, Papas NE, Logar A. The in vitro effects of bupivacaine on articular chondrocytes. J Bone Joint Surg Br 2008;90:814-820.

10. Hansen BP, Beck CL, Beck EP, Townsley RW. Postarthroscopic glenohumeral chondrolysis. Am J Sports Med 2007;35:1628-1634.

11. Serrato JA Jr, Fleckenstein CM, Hasan SS. Glenohumeral chondrolysis associated with use of an intra-articular pain pump delivering local anesthetics following manipulation under anesthesia: A report of four cases. J Bone Joint Surg Am 2011;93:91-98. e99.

12. Matsen FA 3rd, Papadonikolakis A. Published evidence demonstrating the causation of glenohumeral chondrolysis by postoperative infusion of local anesthetic via a pain pump. J Bone Joint Surg Am 2013;95:1126-1134.

13. Scheffel PT, Clinton J, Lynch JR, Warme WJ, Bertelsen AL, Matsen FA 3rd. Glenohumeral chondrolysis: A systematic review of 100 cases from the English language literature. J Shoulder Elbow Surg 2010;19: 944-949.

14. Bailie DS, Ellenbecker TS. Severe chondrolysis after shoulder arthroscopy: A case series. J Shoulder Elbow Surg 2009; 18:742-747.

15. Anderson SL, Buchko JZ, Taillon MR, Ernst MA. Chondrolysis of the glenohumeral joint after infusion of bupivacaine through an intra-articular pain pump catheter: A report of 18 cases. Arthroscopy 2010;26:451-461.

16. McNickle AG, L'Heureux DR, Provencher MT, Romeo AA, Cole BJ. Postsurgical glenohumeral arthritis in young adults. Am J Sports Med 2009;37:1784-1791.

17. Gulihar A, Robati S, Twaij H, Salih A, Taylor GJ. Articular cartilage and local anaesthetic: A systematic review of the current literature. J Orthop 2015;12:S200-210.

18. Kim RJ, Hah YS, Kang JR, Park HB. Antioxidant's cytoprotective effects on rotator cuff tenofibroblasts exposed to aminoamide local anesthetics. J Orthop Res 2015;33: 1001-1007.

19. Sung CM, Hah YS, Kim JS, et al. Cytotoxic effects of ropivacaine, bupivacaine, and lidocaine on rotator cuff tenofibroblasts. Am J Sports Med 2014;42:2888-2896.

20. Haasters F, Polzer H, Prall WC, et al. Bupivacaine, ropivacaine, and morphine: Comparison of toxicity on human hamstring-derived stem/progenitor cells. Knee Surg Sports Traumatol Arthrosc $2011 ; 19: 2138-2144$.

21. Zhang AZ, Ficklscherer A, Gulecyuz MF, et al. Cell toxicity in fibroblasts, tenocytes, and human mesenchymal stem cells-A comparison of necrosis and apoptosis-inducing ability in ropivacaine, bupivacaine, and triamcinolone. Arthroscopy 2017;33:840-848.

22. Scherb MB, Han SH, Courneya JP, Guyton GP, Schon LC. Effect of bupivacaine on cultured tenocytes. Orthopedics 2009;32:26.

23. Friel NA, Wang VM, Slabaugh MA, Wang F, Chubinskaya S, Cole BJ. Rotator cuff healing after continuous subacromial bupivacaine infusion: an in vivo rabbit study. J Shoulder Elbow Surg 2013;22:489-499.

24. Lehner C, Gehwolf R, Hirzinger C, et al. Bupivacaine induces short-term alterations and impairment in rat tendons. Am J Sports Med 2013;41:1411-1418.

25. Nuelle CW, Cook CR, Stoker AM, Cook JL, Sherman SL. In vivo toxicity of local anesthetics and corticosteroids on supraspinatus tenocyte cell viability and metabolism. Iowa Orthop J 2018;38:107-112.

26. Steinmeyer J. [Drug therapy of arthrosis]. Orthopade 2001;30:856-865.

27. Martin SD, Conaway WK, Lei P. Use of intra-articular corticosteroids in orthopaedics. J Bone Joint Surg Am 2018;100:885-891.

28. Batu ED. Glucocorticoid treatment in juvenile idiopathic arthritis. Rheumatol Int 2019;39:13-27. 
29. Bell AD, Conaway D. Corticosteroid injections for painful shoulders. Int J Clin Pract 2005;59:1178-1186.

30. Morita S, Oizumi N, Suenaga N, Yoshioka C, Yamane S, Tanaka Y. Dexamethasone added to levobupivacaine prolongs the duration of interscalene brachial plexus block and decreases rebound pain after arthroscopic rotator cuff repair. J Shoulder Elbow Surg 2020;29: $1751-1757$.

31. Pani N, Routray SS, Mishra D, Pradhan BK, Mohapatra BP, Swain D. A clinical comparison between 0. $5 \%$ levobupivacaine and $0.5 \%$ levobupivacaine with dexamethasone $8 \mathrm{mg}$ combination in brachial plexus block by the supraclavicular approach. Indian J Anaesth 2017;61:302-307.

32. Knezevic NN, Anantamongkol U, Candido KD. Perineural dexamethasone added to local anesthesia for brachial plexus block improves pain but delays block onset and motor blockade recovery. Pain Physician 2015;18:1-14.

33. Watanabe K, Tokumine J, Yorozu T, Moriyama K, Sakamoto H, Inoue T. Particulate-steroid betamethasone added to ropivacaine in interscalene brachial plexus block for arthroscopic rotator cuff repair improves postoperative analgesia. BMC Anesthesiol 2016;16:84.

34. Albrecht E, Vorobeichik L, Jacot-Guillarmod A, Fournier N, Abdallah FW. Dexamethasone is superior to dexmedetomidine as a perineural adjunct for supraclavicular brachial plexus block: Systematic review and indirect meta-analysis. Anesth Analg 2019;128:543-554.

35. Moeen SM, Ramadan IK, Elkady HA. Dexamethasone and dexmedetomidine as an adjuvant to intraarticular bupivacaine for postoperative pain relief in knee arthroscopic surgery: A randomized trial. Pain Physician 2017;20: 671-680.

36. Heshmati F, Zeynali MB, Mohammad Zadeh KH, Mahouri AR. Intra-articular bupivacaine versus bupivacaine plus dexamethasone for analgesia after knee surgery. Iran Red Crescent Med J 2005;8:39-43.

37. Perdreau A, Duysens C, Joudet T. How periarticular corticosteroid injections impact the integrity of arthroscopic rotator cuff repair. Orthop Traumatol Surg Res 2020;106:1159-1166.

38. Hashimoto A, Sonohata M, Hirata H, et al. Periarticular analgesic injection containing a corticosteroid after total hip arthroplasty may prevent deep venous thrombosis: A retrospective comparative cohort study. BMC Musculoskelet Disord 2021;22:19.

39. Kim JI, Kim YT, Jung HJ, Lee JK. Does adding corticosteroids to periarticular injection affect the postoperative acute phase response after total knee arthroplasty? Knee 2020;27:493-499.

40. Peng H, Wang W, Lin J, Weng X, Qian W, Wang W. Local efficacy of corticosteroids as an adjuvant for periarticular cocktail injection in simultaneous bilateral total knee arthroplasty: A prospective randomized double-blind controlled trial. Pain Res Manag 2021;2021:5595095.

41. Wang Q, Tan G, Mohammed A, et al. Adding corticosteroids to periarticular infiltration analgesia improves the short-term analgesic effects after total knee arthroplasty: A prospective, double-blind, randomized controlled trial. Knee Surg Sports Traumatol Arthrosc 2021;29:867-875.
42. Kurosaka K, Tsukada S, Ogawa H, et al. Addition of corticosteroid to periarticular injections reduces postoperative pain following total hip arthroplasty under general anaesthesia: A double-blind randomized controlled trial. Bone Joint J 2020;102-B:1297-1302.

43. Pathonsamit C, Onklin I, Hongku N, Chaiyakit P. Randomized double-blind controlled trial comparing $0.2 \mathrm{mg}$, $0.1 \mathrm{mg}$, and no intrathecal morphine combined with periarticular injection for unilateral total knee arthroplasty. Arthroplast Today 2021;7:253-259.

44. Tammachote N, Kanitnate S, Manuwong S, Yakumpor T, Panichkul P. Is pain after TKA better with periarticular injection or intrathecal morphine? Clin Orthop Relat Res 2013;471:1992-1999.

45. Wei J, Lei GH, Gao SG, et al. Single-dose intra-articular bupivacaine versus morphine after arthroscopic knee surgery: A meta-analysis of randomized-controlled studies. Clin J Pain 2014;30:630-638.

46. Kalso E, Smith L, McQuay HJ, Moore AR. No pain, no gain: Clinical excellence and scientific rigour-Lessons learned from IA morphine. Pain 2002;98:269-275.

47. Gupta A, Bodin L, Holmstrom B, Berggren L. A systematic review of the peripheral analgesic effects of intraarticular morphine. Anesth Analg 2001;93:761-770.

48. Jaureguito JW, Wilcox JF, Cohn SJ, Thisted RA, Reider B. A comparison of intraarticular morphine and bupivacaine for pain control after outpatient knee arthroscopy. A prospective, randomized, double-blinded study. Am J Sports Med 1995;23:350-353.

49. Boden BP, Fassler S, Cooper S, Marchetto PA, Moyer RA. Analgesic effect of intraarticular morphine, bupivacaine, and morphine/bupivacaine after arthroscopic knee surgery. Arthroscopy 1994;10:104-107.

50. Brandsson S, Karlsson J, Morberg P, Rydgren B, Eriksson BI, Hedner T. Intraarticular morphine after arthroscopic ACL reconstruction: A double-blind placebocontrolled study of 40 patients. Acta Orthop Scand 2000;71: 280-285.

51. Jaureguito JW, Wilcox JF, Thisted RA, Phillips C, Cunningham B, Reider B. The effects of morphine on human articular cartilage of the knee: An in vitro study. Arthroscopy 2002;18:631-636.

52. Anz A, Smith MJ, Stoker A, et al. The effect of bupivacaine and morphine in a coculture model of diarthrodial joints. Arthroscopy 2009;25:225-231.

53. van Dorp EL, Morariu A, Dahan A. Morphine-6glucuronide: Potency and safety compared with morphine. Expert Opin Pharmacother 2008;9:1955-1961.

54. Klimas R, Mikus G. Morphine-6-glucuronide is responsible for the analgesic effect after morphine administration: A quantitative review of morphine, morphine-6-glucuronide, and morphine-3-glucuronide. Br J Anaesth 2014;113: 935-944.

55. Case number estimation for unconnected samples and continuous target variables, http://jumbo.uni-muenster.de/ fileadmin/jumbo/applets/fallz.html. Accessed April 7, 2016.

56. Wagenhauser MU, Pietschmann MF, Sievers B, et al. Collagen type I and decorin expression in tenocytes depend on the cell isolation method. BMC Musculoskelet Disord 2012;13:140. 
57. Schulze-Tanzil G, Mobasheri A, Clegg PD, Sendzik J, John T, Shakibaei M. Cultivation of human tenocytes in high-density culture. Histochem Cell Biol 2004;122: 219-228.

58. Pauly S, Klatte F, Strobel C, et al. Characterization of tendon cell cultures of the human rotator cuff. Eur Cell Mater 2010;20:84-97.

59. Tian J, Li Y. Comparative effects of vitamin C on the effects of local anesthetics ropivacaine, bupivacaine, and lidocaine on human chondrocytes. Braz J Anesthesiol 2016;66:29-36.

60. Chiu $\mathrm{CH}$, Chen P, Chen AC, et al. Real-time monitoring of ascorbic acid-mediated reduction of cytotoxic effects of analgesics and NSAIDs on tenocytes proliferation. Dose Response 2019;17:1559325819832143.

61. Marret E, Gentili M, Bonnet MP, Bonnet F. Intra-articular ropivacaine $0.75 \%$ and bupivacaine $0.50 \%$ for analgesia after arthroscopic knee surgery: A randomized prospective study. Arthroscopy 2005;21:313-316.

62. Zhou Y, Yang TB, Wei J, et al. Single-dose intra-articular ropivacaine after arthroscopic knee surgery decreases post-operative pain without increasing side effects: A systematic review and meta-analysis. Knee Surg Sports Traumatol Arthrosc 2016;24:1651-1659.

63. Datapharm, https://www.medicines.org.uk/emc/product/ 1498/smpc. Naropin. Accessed March 15, 2018.

64. Datapharm, https://www.medicines.org.uk/emc/product/ 3619/smpc. Bupivacaine. Accessed March 15, 2018.

65. Ozturk SS, Palsson BO. Effect of medium osmolarity on hybridoma growth, metabolism, and antibody production. Biotechnol Bioeng 1991;37:989-993.

66. Piper SL, Laron D, Manzano G, et al. A comparison of lidocaine, ropivacaine and dexamethasone toxicity on bovine tenocytes in culture. J Bone Joint Surg Br 2012;94: 856-862.
67. Abrams GD, Chang W, Dragoo JL. In vitro chondrotoxicity of nonsteroidal anti-inflammatory drugs and opioid medications. Am J Sports Med 2017;45:3345-3350.

68. Yu XJ, Zhao W, Li YJ, et al. Neurotoxicity comparison of two types of local anaesthetics: Amide-bupivacaine versus ester-procaine. Sci Rep 2017;7:45316.

69. Unami A, Shinohara Y, Ichikawa T, Baba Y. Biochemical and microarray analyses of bupivacaine-induced apoptosis. J Toxicol Sci 2003;28:77-94.

70. Hung YC, Suzuki S, Chen CC, et al. Calcium chloride prolongs the effects of lidocaine and bupivacaine in rat sciatic nerve. Reg Anesth Pain Med 2009;34:333-339.

71. Sverrisdottir E, Lund TM, Olesen AE, Drewes AM, Christrup LL, Kreilgaard M. A review of morphine and morphine-6-glucuronide's pharmacokineticpharmacodynamic relationships in experimental and clinical pain. Eur J Pharm Sci 2015;74:45-62.

72. Beyer A, Koch T, Schroder H, Schulz S, Hollt V. Effect of the Al18G polymorphism on binding affinity, potency and agonist-mediated endocytosis, desensitization, and resensitization of the human mu-opioid receptor. J Neurochem 2004;89:553-560.

73. Tegeder I, Geisslinger G. Opioids as modulators of cell death and survival-Unraveling mechanisms and revealing new indications. Pharmacol Rev 2004;56: 351-369.

74. Iwakiri K, Ohta Y, Minoda Y, Kobayashi A, Nakamura H. Effect of periarticular morphine injection for total hip arthroplasty: a randomised, double-blind trial. Hip Int 2019;29:245-252.

75. Miyamoto S, Sugita T, Aizawa T, et al. The effect of morphine added to periarticular multimodal drug injection or spinal anesthesia on pain management and functional recovery after total knee arthroplasty. J Orthop Sci 2018;23:801-806. 